\title{
Reestruturação Organizacional e Reconstrução da Identidade: um Estudo de Caso em uma empresa de telecomunicações
}

\author{
Daniela Cristina Soares ${ }^{1}$ \\ Adriane Vieira ${ }^{2}$
}

\section{Resumo}

Esta pesquisa teve como objetivo principal analisar o impacto da reestruturação organizacional ocorrida em uma empresa de telefonia celular na identidade dos funcionários. O tema diz respeito às profundas transformações que vêm ocorrendo no mundo do trabalho, derivadas da conjugação entre globalização da economia, inovações tecnológicas e novas formas de gestão. A metodologia adotada é de natureza qualitativa-descritiva e os dados foram coletados por meio de 22 entrevistas semiestruturadas. No plano teórico foram abordados dois temas fundamentais que são as mudanças contemporâneas nas relações de trabalho $e$ seus reflexos sobre a identidade dos trabalhadores. Os resultados da pesquisa mostram que o processo de reestruturação organizacional culminou com a demissão simultânea de 382 funcionários da área de call center e foi conduzido de forma cruel e impiedosa. Os gestores foram informados da decisão da empresa dois dias antes do ocorrido e a atuação da área de Recursos Humanos limitou-se ao atendimento dos aspectos burocráticos. A experiência vivida pelos entrevistados gerou sentimentos de surpresa, decepção, tristeza e angústia, afetando negativamente o processo de construção e reconstrução das identidades.

Palavras-chave: Reestruturação organizacional. Telecomunicações. Call center. Identidade.

\section{Introdução}

A aceleração das inovações tecnológicas, no contexto da globalização da economia, vem provocando uma forte turbulência no ambiente

\footnotetext{
${ }^{1}$ Mestre em Administração pela FEAD. Coordenadora Acadêmica Corporativa dos cursos superiores de tecnologia da Faculdade Pitágoras. Endereço: Rua Mercês, 29, Ap. 501, Prado, Belo Horizonte/MG - Brasil. CEP: 30.410-540.E-mail: danydeb@ig.com.br.

${ }^{2}$ Doutora em Administração pela Universidade Federal de Minas Gerais. Coordenadora, professora e pesquisadora do Mestrado Acadêmico em Administração da Faculdade Novos Horizontes. Endereço: Av. Prof. Mário Werneck, 2859/1002. Buritis. Belo Horizonte/MG - Brasil. CEP 30.575-180.E-mail: adriane.vieira@unihorizontes.br.

Artigo recebido em: 04/10/2008. Aceito em:30/03/2009. Membro do Corpo Editorial Científico responsável pelo processo editorial: Martinho Isnard Ribeiro de Almeida.
} 
empresarial, especialmente nos serviços de telefonia e telecomunicações, essenciais para a transmissão de informações, gerando constantes reestruturações organizacionais que visam obter maior produtividade $e$ rentabilidade.

Para os trabalhadores, um dos reflexos desse contexto tem sido conviver com mudanças caracterizadas, principalmente, pela redução drástica dos empregos formais, permanência menos duradoura nos postos de trabalho, passagem por diversas empresas durante a carreira e tendência ao trabalho autônomo e/ou terceirizado.

Essas mudanças demandam atenção no que se refere ao acompanhamento de seus desdobramentos e busca de solução para os problemas desencadeados, como angústia, sofrimento e adoecimento. Tudo isso interfere diretamente na identidade profissional, construída no meio social $e$ através do exercício do trabalho.

Borzeix e Linhart (1996) constataram, por meio de estudos sobre as relações entre identidade e ação coletiva no interior das organizações, que a identidade não é dada pela posição ocupada pelo indivíduo na instituição ou na categoria profissional à qual pertence, mas construída em função de incidentes e acontecimentos que a alimentam e se atualizam em conformidade com as circunstâncias que lhe conferem voz e forma. Desse modo, um mesmo grupo pode passar por diversas configurações de identidade, nos diferentes momentos de sua história, conforme os recursos oferecidos pelas situações. Toda alteração de sua composição interna, todo rearranjo do ambiente técnico ou organizacional, todo episódio excepcional (como um conflito) pode colocar em questão, de forma momentânea ou definitiva, essa configuração. A identidade coletiva ou social aparece, então, como um "ajuntamento provisório e precário, diretamente ligado às situações sociais de que, em parte, ela é um produto" (BORZEIX; LINHART, 1996, p. 105).

Segundo Freitas (2002), o que tem propiciado o aumento da importância do papel das empresas na construção das identidades é a crise de identidade pela qual passam as pessoas, originada pela ênfase na racionalidade, na quebra das referências culturais e no esfacelamento da ética e da moral. Isso faz com que as pessoas se mostrem receptivas a acatar mensagens e aceitar líderes organizacionais que possam oferecer respostas para as incertezas quanto ao melhor caminho a seguir e que deem um sentido para suas vidas. Contudo, no atual contexto, as organizações têm fornecido apenas referências contraditórias, pois pregam que o indivíduo deve ser combativo, agressivo $e$ 
individualista, ao mesmo tempo em que exigem colaboração e trabalho em equipe. Mensagens incoerentes como essas, somadas à impossibilidade da reciprocidade da energia investida nos vínculos, segundo Sennett (2001), têm corroído o caráter humano, gerando uma ansiedade que afeta os comportamentos, levando as pessoas à desconfiança e ao isolamento, aumentando o individualismo e a competição entre elas.

Nessa perspectiva, surge a proposta deste estudo: analisar os impactos da reestruturação organizacional, ocorrida em uma operadora de telefonia celular, na identidade dos analistas e gestores de equipe envolvidos no processo.

Visando à preservação da identidade da empresa, objeto deste estudo, optou-se por utilizar a identificação genérica de "Empresa Sigma" nas referências à organização pesquisada. Os sujeitos da pesquisa, 22, foram ouvidos por meio de entrevista semiestruturada e dados secundários foram coletados, objetivando complementar as informações. Na sequência deste artigo será apresentado referencial teórico que deu suporte à análise dos dados, abordando os temas: mudanças nas relações de trabalho na contemporaneidade, conceito e construção da identidade e identidade no trabalho. Em seguida são apresentadas as características centrais do caso estudado, o detalhamento da metodologia de pesquisa, a análise e a descrição dos dados coletados, para encerrar, são apresentadas as considerações finais dos pesquisadores.

\section{Referencial Teórico}

\subsection{Mudanças nas Relações de Trabalho na Contemporaneidade}

De acordo com Garcia (2004), a globalização se caracteriza, em parte, por um processo de reorganização da divisão internacional do trabalho, acio-nado pelas diferenças de produtividade e de custos de produção entre países. Antes da III Revolução Industrial, os países semi-industrializados, como o Brasil, apresentavam como característica distintiva o emprego de grande volume de mão de obra de baixo custo, representando um diferencial competitivo em relação aos países desenvolvidos, que contavam com trabalhadores mais qualificados e onerosos. A saída encontrada pelas empresas, para aumentar os lucros e a competitividade no mercado, foi a transferência de boa parte da produção para os países semi-industrializados e, também, o emprego de tecnologia de informação que, por sua vez, provocou a elevação da taxa de desemprego (GARCIA, 2004). 
A III Revolução Industrial é fruto da introdução da tecnologia de informação - TI, um

[...] complexo tecnológico que envolve computadores, softwares, redes de comunicação eletrônicas públicas e privadas, rede digital de serviços de telecomunicações, protocolos de transmissão de dados e outros serviços (CAMPOS; TEIXEIRA, 2004, p. 3),

mas, também é resultante, na visão de Srour (1998), de outras mudanças que afetaram e transformaram o mun do do trabalho, como o modelo de gestão da qualidade que projetou o Japão como exemplo mundial de produção, a partir da década de 1980.

No Brasil, as mudanças nos processos produtivos se fizeram sentir, especialmente, a partir de 1990, com o início da abertura da economia aos produtos importados (COUTINHO; FERRAZ, 1994), quando subitamente acirrou-se a competição interna em função da entrada de competidores internacionais, aumentado significativamente a concorrência em termos de preços e qualidade dos produtos e serviços ofertados. A principal diferença é que, enquanto a maioria dos países ocidentais vivia esse processo há pelo menos 15 anos, o Brasil foi exposto tardiamente ao contexto de globalização de mercados e de inovações tecnológicas. Como consequência, a distância a percorrer pelas empresas brasileiras, em termos de produtividade e qualidade, tornou-se relativamente maior, em relação à de muitos competidores externos.

O certo é que, sob vários aspectos, a III Revolução Industrial se diferencia das anteriores, uma vez que, além do aumento da produtividade no trabalho, isso provocou uma acirrada competição entre as empresas. Nesse cenário, o homem cedeu lugar às máquinas, o aumento do desemprego levou os trabalhadores a melhorarem sua qualificação formal para se tornarem mais facilmente empregáveis e, ao mesmo tempo, surgiram novos postos de trabalho, chamados de precários e/ou informais, como forma de garantir flexibilidade externa às organizações (GARCIA, 2004; HARVEY, 1993).

Se, anteriormente, um tempo longo de permanência na mesma empresa era sinônimo de dedicação, lealdade e compromisso, essa lógica não se aplica aos cenários contemporâneos de downsizing, enxugamento de quadros de pessoal, terceirização e subcontratação, afetando o processo de construção e reconstrução das identidades profissionais (CALDAS, 2000). 


\subsection{A Identidade: conceito e construção}

De acordo com Vieira (2007), o interesse dos teóricos da administração pela temática identidade decorre dos estudos sobre cultura corporativa, mais especificamente da tentativa de entender como e por que os indivíduos se vinculam emocionalmente às organizações, assumindo como seus os valores e regras de comportamentos estabelecidos por elas.

A noção de identidade é complexa, pois adquire vários sentidos em diferentes campos teóricos e mesmo entre correntes do mesmo campo, mas, sem dúvida, foi a corrente psicanalítica que formulou um conceito mais consistente e que mais tem influenciado as ciências sociais.

Segundo Dubar (2005), Freud usou o termo pela primeira vez para descrever os motivos de ter sido atraído ao judaísmo, referindo-se a obscuras forças emocionais e sua relação com o ego, que se tornaram pontos de partida para futuros usos do termo. Conceituar ego e diferenciá-lo do termo self, não é uma tarefa simples. Recorrendo à psicanálise é possível afirmar que o ego é uma parte do sistema psíquico, cuja função principal é mediar as imposições do mundo interno e as limitações do mundo externo. Portanto, o ego, embora seja parte de um sistema psíquico interno, também tem relações com e se diferencia do externo (BOCK;FURTADO; TEIXEIRA; 1995). O termo self foi introduzido na psicanálise em 1950, por Hartmann (1964), quando ele fazia referência à compreensão que o sujeito tem de si mesmo. Simplificando, é como se, de um lado existisse o ego, e de outro, a própria pessoa, o "si mesmo", o self, tendo como interlocutor o "outro", alguém externo.

De acordo com o psicanalista Erikson (1972, apud DUBAR, 2005), o sentimento de identidade é caracterizado pela percepção do indivíduo quanto à própria unidade, ou seja, das semelhanças consigo mesmo, complementado por um sentimento de continuidade, na medida em que ao longo da vida o ego continuamente realiza sínteses internas das experiências vividas. $\mathrm{O}$ autor insiste no fato de que a identidade nunca é instalada, nunca é acabada, visto que o entorno do ego é móvel e que os indivíduos passam, necessariamente, por crises de identidade ligadas a fissuras internas do ego, uma vez que ele vive em discordância com a realidade.

Essa discordância, segundo Dubar (2005), é fruto de uma relação inseparável e conflituosa entre os dois lados da mesma identidade: "identidade para si" e "identidade para o outro". Dado que eu só sei quem sou se, através da comunicação, o outro me informar qual identidade ele me atribui e, a partir daí, eu construir minha própria identidade (DUBAR, 2005). 
Para Dubar (2005), apesar de Max Weber ter desenvolvido uma tradição sociológica, mostrando a importância que deve ser dada à interação "eu outro" na definição do social, foi George Mead, em sua obra intitulada Mind, self and society (1934), quem primeiro descreveu a socialização como o processo de construção de uma identidade social, na relação comunicativa entre o eu e os outros. Pensar em identidade como algo inalterável e estático, segundo Dubar (2005), se torna um erro diante das mudanças vivenciadas ao longo da vida do indivíduo dentro de um grupo.

Para os interacionistas simbólicos, Berger e Luckman (1989), todo indivíduo nasce em uma estrutura social objetiva, dentro da qual encontra os "outros significativos" que se encarregam de sua socialização. A socialização primária é a mais importante para o indivíduo, tendo como objetivo inserir a criança no mundo adulto, fazendo exteriorizar seu próprio ser no mundo social e interiorizar este último, ou seja, apreender ou interpretar um acontecimento objetivo tornando-o subjetivamente significativo para ela. Dessa maneira, a subjetividade do "outro significativo" torna-se objetivamente acessível a ela e dotada de sentido. Quando se fala do "outro significativo" na socialização primária, faz-se referência basicamente aos pais, e é exatamente por isso que ela é tão importante, dado que é carregada de afeto. A socialização secundária, por sua vez, é a interiorização de submundos institucionais ou baseados em instituições. A extensão e caráter dessas instituições são, portanto, determinados pela complexidade da divisão do trabalho e a concomitante distribuição social do conhecimento.

Segundo Berger e Luckman (1989), são necessários graves choques no curso da vida para desintegrar a maciça realidade interiorizada na primeira infância, ou seja, os valores que orientam o comportamento; enquanto a interiorização de normas e regras se prolonga durante toda a vida do indivíduo, tendo em vista a sua participação em novos grupos sociais. De acordo com Vasconcelos e Crubellate (2003), dessa maneira, a corrente interacionista simbólica concilia o pressuposto weberiano de liberdade de escolha humana com um modelo, segundo o qual, o sistema de valores é anterior a todos os outros sistemas sociais. Ou seja, as crenças e valores dos indivíduos forneceriam os limites para a ação e a escolha.

Para Vasconcelos e Crubellate (2003), o representante da corrente cognitivista, Sainsaulieu (1977), diferentemente dos interacionistas simbólicos, considera a ação humana menos determinada pelos valores incorporados na socialização primária. Para ele, a identidade é construída a partir de um processo complexo de aprendizagem cultural, em que o indivíduo reconhece 
a si mesmo pelo que é idêntico e o que é diferente, tendo sempre por referência um "outro".

É essa noção de identidade que será trabalhada neste artigo, remetendoa ao local de socialização secundária que é a empresa, cujo "eu" luta pelo reconhecimento de si próprio pelos "outros", ou seja, pelo reconhecimento social do seu valor.

\subsection{Identidade no Trabalho}

Segundo Sainsaulieun (1977), a busca do reconhecimento social é sempre uma experiência conflituosa, na qual o sistema individual da personalidade concorre com o sistema social, ou seja, de um lado está o sujeito, buscando expressar seus desejos e se apropriar de objetos, e de outro está a estrutura social, composta por outros sujeitos com desejos que, na maior parte das vezes, concorrem com os seus. A identidade, portanto, é resultante do jogo de relações envolvidas na busca do sujeito pela expressão dos seus desejos individuais, que é sempre uma luta de poder.

A luta pelo desejo de poder, diz Sainsaulieu, não é um fim em si, mas um sinal social de um jogo mais profundo da personalidade, que se insere no coração de toda relação prolongada (SAINSAULIEU, 1977). Como alertam Vasconcelos e Crubellate (2003), essa é sempre uma disputa entre desejos concorrentes em situações de desigualdade, vividas, por exemplo, no ambiente do trabalho, pois aqueles que têm acesso aos meios concretos de impor suas ideias podem levar o outro a uma situação de "morte simbólica", fortemente presente nos processos de demissão, em função da sua exclusão do sistema e da perda dos vínculos sociais e da ligação que havia entre a pessoa e seus objetos: a empresa, o chefe e os pares, além do próprio trabalho.

O conceito de identificação é essencial para o entendimento de como se processa essa relação "eu" e "outro". A identificação, de acordo com Freitas (2002), é um processo que apresenta duas acepções: o reconhecimento de algo ou de alguém e o reconhecer-se em algo ou em alguém. Nesse processo, quanto maior a congruência entre as normas e valores do grupo $e$ as do próprio indivíduo, resultantes do processo de socialização primária, maior a possibilidade de internalização e de identificação.

$\mathrm{O}$ ato de desejar é mantido pela possibilidade concreta de obter o que se deseja dentro das relações de poder que o envolvem. É preciso que os indivíduos tenham a possibilidade de vencer pelo menos algumas vezes para 
que possam sair da cadeia permanente de identificações com os outros e afirmar sua própria individualidade. Situações de mudanças, que envolvem demissões e realocações, podem promover o sentimento de dissolução ou de mutilação de aspectos elementares da própria individualidade, dando a ideia de perda da identidade.

Nessa situação, de acordo com Vasconcelos e Crubellate (2003, p. 12),

[...] os recursos intelectuais, afetivos e cognitivos por ele desenvolvidos no passado, os seus valores e sua visão de mundo, podem não ser mais suficientes para ajudá-lo a compreender, decidir e agir na situação presente.

Ainda, segundo os autores, o confronto com seus próprios valores será mais forte à medida que o indivíduo se sinta oprimido pela nova realidade. Na tentativa de compreendê-la, ele irá rever sua lógica de ação e buscará uma nova visão de mundo que lhe permita encontrar novos meios de ação.

Uma estratégia de sobrevivência, segundo Luhmann (1988, apud VASCONCELOS; CRUBELLATE, 2003), seria abandonar a confiança inocente apoiada em crenças e optar por uma atitude de confiança esclarecida, isto é, baseada nos conhecimentos dos riscos implicados na ação. Giddens (1991), por sua vez, discorda dessa posição por não acreditar que os indivíduos estejam sempre conscientes dos riscos implicados na situação de vínculo institucional, uma vez que elas são sempre mais emocionais do que cognitivas.

De qualquer forma, essa busca por novas estratégias de ações não é realizada sem que se sintam os seus efeitos sobre a psique humana, que podem ser mais ou menos desestruturantes, dependendo do significado que cada indivíduo atribuiu ao trabalho. No caso das demissões, Caldas (2000) aponta pelo menos sete tipos de efeitos a serem enfrentados:

a) Emocionais: angústia, ansiedade, frustração.

b) Psicológicos: baixa na autoestima.

c) Físicos: doenças.

d) Comportamentais: novos hábitos.

e) Familiares: divórcio.

f) Econômicos: queda no padrão de renda.

g) Profissionais: nova área de atuação.

h) Sociais: reconhecimento. 
Nos remanescentes, ou seja, naqueles que foram poupados dos processos de reestruturação organizacional, os efeitos sentidos seriam, principalmente, os de caráter emocional, psicológico e comportamental.

O certo é que, no atual estágio de modernização da sociedade e das relações de trabalho, marcado pela intensificação da velocidade e amplitude das mudanças, é possível afirmar que a construção das identidades acontece sob condições bastante desfavoráveis aos indivíduos, que para sobreviverem às situações percebidas como adversas e imporem suas diferenças precisam, primeiro, encontrar alguma coerência nelas; o que é uma tarefa bastante difícil de ser executada.

A construção teórica aqui desenvolvida tem por objetivo permitir a análise dos dados empíricos coletados junto a funcionários de uma empresa de telefonia celular que passaram por um processo de reestruturação organizacional. O tipo de mudança realizada, conforme será visto adiante, pode ser classificado como perversa e impiedosa (SILVA; VERGARA, 2003, p. 18), "não só porque envolveu um grande número de trabalhadores, mas porque eles foram tratados como objetos descartáveis". O interesse intelectual repousou, então, sobre os efeitos da decisão no processo de construção e reconstruções das identidades no trabalho.

\section{Caso Estudado}

A Sigma, empresa escolhida como objeto de estudo nesta pesquisa, é uma organização multinacional que atua no setor de telecomunicações, mais especificamente em tecnologia celular. Essa empresa começou a operar no Brasil em 1998, com o lançamento do serviço TDMA no estado da Bahia e, na sequência, em outros dez estados das regiões Sul, Sudeste e Nordeste.

Em 2002, a empresa foi a primeira operadora a lançar o serviço GSM no Distrito Federal e em todo o Centro-Oeste, assim como nos estados de São Paulo e Rio Grande do Sul. A Sigma foi pioneira, também, no lançamento do primeiro serviço de mensagens multimídia, que permite o envio de fotos, sons e texto em uma única mensagem para qualquer endereço de e-mail ou para outro celular, utilizando a tecnologia MMS (Multimedia Messaging Service). Em seguida, lançou a videomensagem, primeiro serviço do Brasil que permite a gravação de vídeos sonoros de até 40 segundos e seu envio para um endereço de e-mail. 
Ao longo de 2004 e 2005, a Sigma prosseguiu em sua trajetória de pioneirismo, lançando soluções como o primeiro celular com Windows Móbile Second Edition 2003, o mininotebook Nokia 9500 Communicator, o Palm Treo 650, o Qtek 9090 e o Nokia E61.

No final de 2005, a empresa inaugurou suas novas instalações na cidade de Santo André, estado de São Paulo, onde foi construída a maior central de atendimento do Brasil e transferida parte das operações de teleatendimento que eram realizadas em Minas Gerais, provocando demissões e realocações de funcionários.

\section{Metodologia da Pesquisa}

Esta pesquisa está apoiada em uma abordagem qualitativa, em função da natureza dos dados que precisavam ser coletados (comportamentos e percepções), e da importância do papel do pesquisador na condução da investigação, uma vez que os sujeitos da pesquisa passaram por uma difícil experiência. Para os que foram demitidos sobrou a tarefa de lidar com as emoções da perda de vínculo e da rejeição; para os que ficaram e foram realocados, a de lidar com a ausência dos colegas e chefias que serviam de referência e fonte de identificação.

Quanto aos meios de investigação, optou-se pela realização de um estudo de caso, que de acordo com Trivinõs (1987, p. 110) "tem por objetivo aprofundar a descrição de determinada realidade". O caso estudado é o da empresa Sigma e a unidade de análise é a área de call center com seus funcionários demissionários, demitidos e realocados, ocupantes dos cargos de analistas e gestores.

A escolha dos sujeitos de pesquisa se deu pelo critério de acessibilidade por parte dos pesquisadores. Outro critério utilizado foi o da "bola de neve", ou seja, a indicação de novos sujeitos pelos próprios participantes. O encerramento da coleta de dados aconteceu quando, naturalmente, nenhum dado novo foi acrescentado. Assim, chegou-se a um total de 22 sujeitos. As entrevistas foram registradas em meio eletrônico e, posteriormente, transcritas com o propósito de permitir a análise das falas. 
A Tabela 1 sintetiza a situação profissional dos entrevistados no momento da pesquisa.

Tabela 1: Situação Profissional

\begin{tabular}{|l|c|c|c|}
\hline Cargo/Situação & Gestores & Analistas & Total \\
\hline Demitidos & 2 & 7 & 9 \\
\hline Realocados & 4 & 6 & 10 \\
\hline Saída espontânea & 1 & 2 & 3 \\
\hline Total & 7 & 15 & 22 \\
\hline
\end{tabular}

Fonte: Dados da pesquisa (2007)

Dezessete sujeitos estavam na faixa etária de 25 a 29 anos e cinco na de 25 e 34 anos. Quanto ao nível de escolaridade, 14 entrevistados declararam ter o terceiro grau, sendo que destes, seis tinham concluído pósgraduação lato sensu e dois o curso de mestrado. Quanto ao "tempo de casa", 11 estavam na empresa há mais de quatro anos.

Para preservar a identidade dos entrevistados, eles serão identificados na descrição e análise do conteúdo das entrevistas, por siglas: G (gestor) e A (analistas). Associadas à situação funcional deles: $\mathrm{D}$ (demitido), $\mathrm{R}$ (realocado) e S (saída espontânea). Essas identificações estão acompanhadas de um número aleatório, apenas para diferenciar as falas dos sujeitos.

Para a análise dos dados obtidos optou-se por empregar a técnica denominada "análise de conteúdo" do tipo temática, que tem o propósito de obter subsídios para a elaboração de inferências consistentes, com base em conceitos teóricos estudados.

Na sequência, será descrita e analisada a forma como o processo de reestruturação foi conduzido, o dia da demissão, a participação dos gestores e da área de Recursos Humanos e os impactos da mudança na construção das identidades no trabalho. 


\section{Apresentação e Análise dos Resultados}

\subsection{A Condução do Processo de Reestruturação Organizacional}

Segundo Wood Jr. (1995, p. 190),

[...] mudança organizacional é qualquer transformação de natureza estrutural, institucional, estratégica, cultural, tecnológica, humana, ou de qualquer outro componente, capaz de gerar impacto em partes ou no conjunto da organização.

A mudança colocada em curso na Sigma pode ser classificada como de natureza estratégica e estrutural, uma vez que a empresa decidiu transferir os serviços de atendimento aos clientes de Minas Gerais, principalmente, para a nova central de atendimento construída em Santo André/SP, justificada pela necessidade de otimizar e racionalizar a operação desse serviço. foram demitidos 382 funcionários de uma só vez, e a notícia foi dada por meio de nota à imprensa no dia 2 de junho de 2006, véspera da Copa Mundial de Futebol, de forma a reduzir o interesse da mídia pelo assunto.

Nessa mesma nota, a empresa informou a contratação de 477 novos colaboradores para posições de atendimento em outros Estados, e que os desligados receberiam um "pacote" de benefícios criado pela empresa $e$ negociado com o sindicato da categoria. Essa estratégia, segundo Caldas (2000), é comumente utilizada pelas empresas que optam pela demissão em massa, como forma de minimizar os efeitos da decisão tanto no âmbito interno quanto externo, ou seja, sua imagem perante os funcionários e os clientes.

Os funcionários tomaram conhecimento do processo de reestruturação da Sigma através de boatos que começaram a circular cinco meses antes de seu efetivo desfecho, cuja proporção foi se ampliando a ponto de os levarem a acreditar que realmente haveria demissão em massa. Alguns iniciaram a busca por uma nova oportunidade de trabalho em outras empresas do mercado, enquanto outros permaneceram na Sigma com a expectativa de serem realocados.

A divulgação foi meio por boca a boca mesmo, aquela "rádio-peão". E, hora ou outra vinha o nosso supervisor nos posicionando sobre o que estava acontecendo, até porque 
a gente indagava muito: "Vai mudar? Não vai mudar?". Muitas vezes, eles não tinham muita clareza do que iria acontecer. Mas, às vezes, eles buscavam essa instrução para a gente. Então, era dessa forma que a gente ficava sabendo (AS2).

A queda da produtividade, a perda da motivação e o aumento da ansiedade foram alguns dos efeitos apontados pelos entrevistados, em razão da falta de direcionamento e de perspectivas quanto ao seu futuro.

Próximo da reestruturação, praticamente não tinha mais demanda. [...] Eu sentia que realmente não tinha mais trabalho para ser feito. As atividades, praticamente todas, já haviam sido repassadas para a matriz. Acabei ficando ansioso nos instantes próximos à reestruturação (AR1).

Houve desânimo, falta de motivação, constante busca por outra oportunidade fora da empresa. Tudo isso (AD2).

Uma insegurança total. Você sabia que algo estava acontecendo ali, mas ninguém confirmava nada. Você via funções sendo transferidas para uma área da matriz. Você fica: "Ué... a próxima pode ser a minha". E aí? Vou ser reaproveitado? Não vou? E a empresa falando o tempo todo: "Não, a área não vai acabar". Assim, a gente se sente ameaçado, inseguro, né? (AS1).

Os momentos vividos foram comparados pelos entrevistados com o programa Big Brother Brasil, exibido pela Rede Globo de Televisão, uma vez que a todo instante aguardavam a eliminação de todos ou de parte da equipe.

\subsection{O Dia da Demissão}

No início da manhã do dia da demissão alguns funcionários receberam uma mensagem pelo celular, enviada pelas gerências, solicitando-os a comparecerem a uma reunião. Quando chegaram à empresa encontraram seguranças posicionados na frente do prédio e em todos os andares do edifício. Foram, então, reunidos num auditório e comunicados pelos gerentes de que todos seriam desligados ao mesmo tempo. Após assinarem as cartas de demissão e serem informados pela área de Recursos Humanos sobre os benefícios 
a que tinham direito, os ex-funcionários foram escoltados pelos seguranças para fora das instalações da empresa e advertidos de que não poderiam retornar.

Foi um choque. Ninguém esperava que no dia da demissão pudesse estar ocorrendo aquilo. E foi uma cena marcante ver os colegas de trabalho sendo demitidos $e$ pensar que muita gente ali poderia ter outra chance. Eu achei uma falta de respeito. As pessoas iam chegando e tendo que assinar uma carta de demissão (AR1).

No dia anterior as pessoas saíram sem saber o que iria acontecer. As pessoas perderam o acesso às suas estações de trabalho durante a madrugada desse dia. Então, todos foram surpreendidos no momento em que chegaram e não conseguiram logar seus computadores, não conseguiam efetivamente fazer nada. Percebiam a presença de todos os gestores já de manhã. Então, foi muito negativo, porque foi muito brusco a forma como aconteceu. Chegou $e$ acabou de um dia para o outro (AR2).

A experiência vivida pelos entrevistados gerou sentimentos de decepção, tristeza, surpresa, angústia e, por isso mesmo, pode ser classificada como perversa e impiedosa (SILVA; VERGARA, 2003), uma vez que além de envolver um grande número de trabalhadores, o uso da força repressiva se fez presente.

É preciso salientar que situações de angústia e sofrimento são difíceis de serem esquecidas e exercem influência negativa na construção da identidade pessoal e social do sujeito, afetando significativamente os novos relacio-namentos. Além disso, o constrangimento a que foram submetidos os demitidos, aos quais foi empregado tratamento rude e desrespeitoso, agravou a intensidade do impacto sofrido.

\subsection{A Participação dos Gestores e da Área de Recursos Humanos no Processo}

A falha no processo de comunicação foi o principal motivo de queixa por parte dos entrevistados. Quando os boatos tiveram início, eles afirmaram que buscaram suas chefias para esclarecimentos as quais nada puderam acrescentar, aumentando o desconforto. 
[...] péssima comunicação entre empresa e funcionário, falta de transparência [...] falta de possibilidade de a empresa permitir ao funcionário buscar um outro caminho diante do que ia acontecer (AD2).

Os gestores, por sua vez, revelaram que desconheciam por completo as decisões da empresa e que se sentiram impotentes diante da situação. Ao mesmo tempo, como revela o depoimento a seguir, havia uma necessidade de compreender e racionalizar o ocorrido, revelando um conflito típico do papel desempenhado: o de gerente, que deve preocupar-se com o desempenho e a imagem institucional, e o de líder, que deve levar em consideração as necessidades da equipe.

[...] naquele momento, eu era um representante da empresa respondendo às perguntas que me eram feitas. [...] Eu queria ter clareza para responder. Nisso a empresa poderia ser transparente e não foi. Os gestores eram peças fundamentais e só ficaram sabendo na véspera o que realmente aconteceria. Agora, se você me perguntar assim: você entende o que a empresa fez? Eu entendo perfeitamente, porque a área de relacionamento está em contato on-line com o cliente. Não é aquela coisa que você ficou sabendo através de uma revista. Se divulgassem a informação, o cliente saberia, e os reflexos disso poderiam ser drásticos. Ter escondido as informações dos gestores foi algo desnecessário, porque os gestores poderiam inclusive ter colaborado para um processo de reestruturação mais ameno (GR4).

A opinião dos entrevistados sobre o papel da área de Recursos Humanos da Sigma, no processo de reestruturação organizacional, aponta, de forma consensual, para a omissão, por se limitar ao atendimento de aspectos legais e burocráticos, ou seja, aos benefícios, sem se atentar para as questões emocionais envolvidas.

Eu não senti o papel deles. Acho que eles não trabalharam, eles não falaram nada. Simplesmente não existiu o RH na empresa (AD3).

Fraco, sem comunicação. A partir do momento em que eu tive a oportunidade de continuar lá ou de sair, eles foram lentos nas decisões, nas informações que eles me presta- 
ram. Então, eu acho que o $\mathrm{RH}$ foi muito ausente nesse momento (AD2).

Além disso, os entrevistados mencionaram a falta de iniciativa no sentido de promover de forma mais eficiente a realocação dos funcionários em outras unidades de negócio da empresa, ou mesmo em empresas parceiras, o que poderia ter minimizado o desgaste emocional e, até mesmo, evitado prejuízos à imagem interna da organização. Observa-se que tais ações são esperadas de empresas socialmente responsáveis e também evitam a perda de pessoal qualificado, que são os verdadeiros ativos de uma organização.

O processo de realocação também foi falho e desorganizado. Eu não sei falar se os Recursos Humanos ficou sabendo também dessa reestruturação em cima da hora. Mas, se não ficou, houve uma falha, porque o contato do pessoal de Recursos Humanos com quem poderia ficar ou poderia ser remanejado foi muito em cima da hora. E eu acho que, por ser em cima da hora, não conseguiram contatar as pessoas para realocar. Pessoas boas, que tinham um trabalho bom não tiveram chance de continuar na empresa (AR1).

\subsection{A Identidade no Trabalho em Reconstrução}

Para Sainsaulieu (1977), a identidade está relacionada ao sentimento de permanência e continuidade que o indivíduo experimenta em suas relações sociais e que ele perde no caso de pressões externas. A pergunta que norteou esta pesquisa era se o processo de demissão e realocação teria provocado nos sujeitos o sentimento de perda ou mesmo crise da identidade no trabalho. Iniciou-se a investigação desse tema pedindo aos sujeitos que definissem identidade no trabalho $e$ as respostas obtidas foram as seguintes:

Identidade no trabalho é tudo aquilo que está relacionado com a sua identidade com a empresa. São os valores que a empresa prega e os que você tem. O seu valor juntamente com o valor da empresa (GR1)

Eu acho que a identidade no trabalho vai sendo construída durante a trajetória profissional da pessoa. Acho que ela 
tem a base de caráter mesmo da pessoa. Acho que já vem alguma coisa de berço, vamos dizer assim. Mas acho que ela vai sendo construída. A pessoa vai criando a identidade na medida em que ela vai trabalhando, vai se deparando com situações, com problemas, com coisas boas, coisas ruins (AD4).

Identidade no trabalho, para mim, é quando você começa a identificar os seus valores nos valores da empresa, quando você começa a achar que tudo aquilo que você faz está realmente condizendo com o que você esperaria de uma empresa (AS2). Identidade no trabalho é se você se identifica com a empresa, qual é a sua percepção da empresa, qual é a afinidade que você tem com a organização, o que a organização tem de semelhante com você, com o que você acredita, com o que você espera da empresa (AR3).

Como é possível constatar, há uma clara coincidência entre o conceito de identidade no trabalho para os sujeitos da pesquisa, com aquele expresso na referencial teórico. Os sujeitos relacionam identidade com a congruência entre os valores que o indivíduo traz consigo, desde o seu processo de socialização primária, com aqueles que a organização assume como seus. Ao mesmo tempo, entendem que a identidade não é algo pronto, mas um processo em construção, resultante dos diversos confrontos entre os desejos do sujeito e o desejo dos outros, nas relações sociais e de poder que se estabelecem nos locais de trabalho. Também chamam a atenção para a importância dos processos de identificação na construção da identidade.

Em diversas vezes, principalmente nas épocas onde eu tinha possibilidade de sair, aí, a empresa fazia uma contraproposta. E, por ter essa identificação com a empresa, eu resolvi ficar (AR5).

Na maioria dos momentos, eu me senti parte da empresa. Alguns momentos, não. Eu acho que é baseado principalmente em situações. A gente passa por algumas situações na empresa com as quais a gente não concorda (AS2).

Os depoimentos revelam que as identificações e, também, as identidades são ameaçadas por situações de discordância entre os desejos dos sujeitos e a impossibilidade de realizá-los, por haver um confronto direto com o desejo 
do outro, no caso a organização, com suas metas, processos e normas procedimentais. De acordo com Sainsaulieu (1977), o sujeito dispõe de um passado cultural, de hábitos adquiridos através dos processos de identificação característicos de sua socialização primária e secundária, mas o universo social do trabalho pode representar uma realidade totalmente diferente da passada, obrigando-o a confrontar características de percepção, análise e julgamento do passado com aptidões necessárias à situação presente.

Quando questionados sobre quais são os valores da empresa Sigma, os entrevistados citaram: transparência, comprometimento, respeito, profissionalismo, criatividade, velocidade e valorização dos funcionários. Na sequência, afirmaram que havia uma forte correlação entre os valores da Sigma e os valores prezados por eles; pelo menos até o início das mudanças. Segundo eles, foi nesse momento que perceberam que alguns dos valores presentes no código de condutas da empresa não estavam sendo colocados em prática.

Eu senti que priorizaram alguns valores em detrimento de outros. Eu acho que em algumas situações é muito difícil você manter todos os valores vigentes para tomada de decisão. Então, o que eu vi no processo de reestruturação foi isso. Optou-se por alguns valores em detrimento de outros (AD7).

Um dos valores que tinha era essa questão da transparência. Então, quando houve essa transformação, realmente essa identificação se perdeu (AR6).

Primeiro, a confiança. Foi perdida totalmente. E, em determinados momentos, faltou respeito (AS1).

De acordo com Vasconcelos e Crubellate (2003), quando valores anteriores não asseguram mais o sucesso nas relações presentes, a aprendizagem de novas capacidades estratégicas pode levar os indivíduos a tomar consciência de outras lógicas de ação e de realidade, diferentes daquelas herdadas de socializações passadas. Luhmann (1988, apud VASCONCELOS; CRUBELLATE, 2003), por sua vez, acredita que nessas situações os indivíduos são capazes de substituir uma confiança inocente por uma esclarecida, baseada nos mapeamento dos riscos da ação. Nesse sentido, buscou-se através da entrevista verificar se os sujeitos consideravam superadas as frustrações e angústias vividas no processo de mudança estrutural ou se isso havia impactado fortemente as 
identidades no trabalho, provocando rupturas e crises, ao ponto de dificultar a reconstrução dessas identidades em novos contextos.

Foi completamente superado. Isso não é a primeira vez que ocorreu nem vai ser a última, com certeza. Em grandes empresas, em mercados dinâmicos como esse de telecomunicações, as empresas estão sujeitas a isso e os funcionários também (AD2).

Não vou dizer que foi superável, não, porque até hoje ainda há resquícios dessa reestruturação, da forma como foi conduzida, do que aconteceu. No outro dia, quando cheguei e vi a empresa toda vazia, foi algo, assim, muito diferente. A empresa parecia até ser empresa fantasma, porque mais da metade dos funcionários foi demitida (AR1)

Algumas pessoas superaram. Mas, há sequelas e você fica um pouco temeroso diante do mercado. Você não sabe: Poxa, será que fui eu que errei? Será que a culpa foi minha? Você fica bem abalada. Eu estou falando por mim, fiquei bem abalada diante de algumas situações (AD2)

$\mathrm{Eu}$ acho que, se a pessoa perdeu a identidade, talvez a forma como ela construiu a identidade dela não tenha sido a melhor, porque identidade é algo pessoal. Você não tem que construir sua identidade em cima de alguém ou de alguma coisa. Eu não tenho que construir minha identidade em cima da Sigma. Eu não tenho que construir minha identidade emocional em cima do meu marido. Ele pode ir embora, ele pode morrer, a Sigma pode falir. Eu não acredito que as pessoas perderam a identidade porque isso é muito forte; mas, talvez elas tenham tido um percalço em termos de identidade. Passaram por uma situação difícil, por confusão e tal. Ela saiu dali, ela vai buscar outro caminho. Se for um bom profissional que tem suas convicções, vai ser um bom profissional em qualquer outra empresa (GR1)

Ao concluir esta investigação é possível inferir, pelos depoimentos coletados, que a experiência da demissão, mesmo conduzida de uma maneira tão impiedosa é superável, contudo provoca efeitos extremamente negativos na psique humana, como: angústia, ansiedade, frustração; baixa na autoestima; falta de reconhecimento (CALDAS, 2000). Os demitidos fizeram menção, também, à queda no padrão de renda e às dificuldades de honrarem 
compromissos já assumidos, além da questão da procura de novo emprego num mercado mais exigente e competitivo. Tudo isso, naturalmente dificulta o processo de reconstrução das identidades, principalmente pelas quebras sucessivas dos vínculos de confiança, no entanto, não é possível afirmar que alguns dos entrevistados tenham passado por fortes rupturas emocionais. A superação é possível, mas não totalmente e tampouco rapidamente.

Percebeu-se, sim, uma fragilização da estrutura psicológica quando um dos entrevistados manifestou suas dúvidas quanto à própria responsabilidade pela demissão, ou uma internalização de culpa, fenômeno já identificado por Dejours (1993) e Sennet (2001) nas suas pesquisas sobre a temática.

É possível identificar, também, nos depoimentos anteriores, a necessidade de adotar uma consciência mais esclarecida, ainda que não se tenha a visão global dos riscos, conforme Giddens (1991), quando afirma que fenômenos como esses estudados serão cada vez mais comuns em mercados tão dinâmicos e instáveis e, que, portanto, as pessoas devem estar preparadas para passar por situações semelhantes ao longo de sua vida profissional. Nota-se também a presença do que Sennett (2001) denomina de "fundamentalismo narcisista" ou uma exacerbação do individualismo, como se a construção da identidade pudesse ou devesse ocorrer sem a presença do "outro", uma vez que ele sempre pode faltar.

Em síntese, é possível afirmar, parafraseando Vasconcelos e Crubellate (2003), que a excessiva fragmentação e descontinuidade das relações de trabalho impõem sérias restrições à possibilidade de relações afetivas duradouras, e que as mudanças constantes e a individualização dos riscos, fortemente presentes na contemporaneidade, dificultam a sobrevivência humana, uma vez que é quase impossível para os indivíduos imporem suas diferenças e encontrarem alguma coerência nas ações e acontecimentos.

\section{Considerações Finais}

Os resultados da pesquisa revelaram que o processo de reestruturação da operadora de telefonia celular Sigma foi mal conduzido, dentro da perspectiva humana. A demissão de 382 funcionários em 2006 foi planejada pela cúpula da organização. O processo de comunicação não foi estruturado e possibilitou que informações extraoficiais fossem divulgadas, permitindo que os funcionários chegassem a vários tipos de interpretações e conclusões. 
A principal queixa apresentada pelos entrevistados foi a falta de transparência, exatamente um dos principais valores presentes no código de ética da empresa.

Constatou-se que a reestruturação interrompeu a vivência simbólica que os indivíduos construíram na empresa e com seus colegas, e, apesar de todos terem consciência da não estabilidade dos seus empregos no mundo contemporâneo, consideram a experiência traumática e desrespeitosa.

A pesquisa evidenciou que os gestores foram comunicados do processo de demissão somente uma semana antes da consumação do fato. Declararamse extremamente decepcionados, pelo fato de atuarem em cargos de confiança e não terem a oportunidade de opinar durante o processo, nem propor sugestões que minimizassem o sofrimento dos membros de suas equipes.

Informações sobre o processo apenas foram oficialmente repassadas aos funcionários no dia da demissão, em contexto de constrangimento $e$ humilhação, diante do aparato de segurança que os obrigava a "sair pela porta dos fundos". Na percepção dos funcionários, eles foram descartados pela empresa, tratados como meros objetos, como se a organização gerisse "coisas" e não seres humanos.

Verificou-se que os reflexos emocionais, tais como tristeza, angústia e decepção contribuíram para tornar difícil qualquer tentativa de compreensão dos fatos, naquele momento. Os demitidos revelaram seus esforços no sentido de focar mais o presente e o futuro e ver os acontecimentos do passado como algo que lhes "abriu os olhos" e os levou a buscar novas oportunidades.

Por ocasião das entrevistas todos os ex-funcionários entrevistados já estavam realocados e, cada um a seu modo, revelou estar buscando reestruturar a vida profissional pós-demissão de forma positiva. Contudo, parece ser prematuro concluir que os impactos da demissão foram totalmente superados.

Diante dos dados coletados, entende-se que é chegado o momento de as empresas perceberem a importância e a necessidade de uma análise multidisciplinar, levando em consideração as contribuições da psicologia, a fim de refletir sobre possíveis formas de minimização dos seus efeitos de demissões coletivas conduzidas dessa maneira.

Enfim, acredita-se que deve ser dedicada atenção especial ao fato de que um processo de reestruturação mal conduzido traz graves implicações nas dimensões: subjetiva e intersubjetiva, bem como na identidade das pessoas, afetando diretamente os mecanismos de geração de significados. 


\section{Organizational Restructuring and Reconstruction of Identity: A Case Study in the Company of Telecommunications}

\section{Abstract}

The main objective of this research is to analyze the impacts that re-structuring the telephone operators at the cellular operators has on the identity of the workers. The theme talks about the profound transformations which occur in the world of work, derived from the link between globalization and the economy, the ongoing advancements in technology and the new immerging forms of Company management. The methodology adopted is of qualitative nature whose data was collected by means of semi-structured interviews. Theoretically speaking, this research boarders two fundamental themes; the current changes that occur in relationships at the workplace and the effects these changes have on the identity of professionals. The survey results show that the process of organizational restructuring culminated with the simultaneous resignation of 382 officials from the area of call center and was conducted in a cruel and merciless. The managers were informed of the decision by the company two days before the action occurred and the area of human resources was limited to bureaucratic aspects of care. The experience generated by the interviewees feelings of surprise, disappointment, sadness and anguish, affecting negatively the process of construction and reconstruction of identities.

Key-words: Organizational restructuring. Telecommunications. Call center. Identity.

\section{Referências}

BERGER, P.; LUCKMANN, T. A construção social da realidade. Petrópolis: Vozes, 1989.

BOCK, A. M.; FURTADO, O.; TEIXEIRA, M. de L. Psicologias: uma introdução ao estudo da psicologia. São Paulo: Saraiva, 1995.

BORZEIX, A.; LINHART, D. E. Identidade e práticas lingüísticas na empresa. In: CHANLAT, J. F. (Org.). O indivíduo na organização: dimensões esquecidas. 2. ed, v. 3. São Paulo: Atlas, 1996. 
CALDAS, M. P. Demissão: causas, efeitos e alternativas para empresa e indivíduo. São Paulo: Atlas, 2000.

CAMPOS, E.; TEIXEIRA, F. L. C. Adotando a tecnologia de informação: análise da implementação de sistemas de "groupware". RAE-eletrônica. São Paulo, v. 3, n. 1, 2004.

COUTINHO, L.; FERRAZ, J. C. Estudo de competitividade da indústria brasileira, Campinas: Unicampus/Papirus, 1994.

DEJOURS, C. Uma nova visão do sofrimento humano nas organizações. In: CHANLAT, J. F. (Org.). O indivíduo nas organizações: dimensões esquecidas. 2. ed., v. 1. São Paulo: Atlas, 1993.

DUBAR, C. A socialização: construção das identidades sociais e profissionais. São Paulo: Martins Fontes, 2005.

ERIKSON, E. Adolescente et crise - la quête de l'identité. Paris: Flammarion, 1972. In: DUBAR, C. A socialização: construção das identidades sociais e profissionais. São Paulo: Martins Fontes, 2005.

FREITAS, M. E. de. Cultura organizacional: identidade, sedução e carisma? 3. ed. Rio de Janeiro: Editora FGV, 2002.

GIDDENS, A. As conseqüências da modernidade. São Paulo: UNESP, 1991.

GARCIA, F. C. Globalização, emprego e empregabilidade. Revista Gestão e Planejamento, ano 5, n. 10, Salvador, jul./dez., 2004, p. 91-95.

HARTMANN, H. Essays on ego psychology: selected problems in psychoanalytic theory. New York: International Universities Press, 1964.

HARVEY, D. A condição pós-moderna: uma pesquisa sobre as origens da mudança cultural. 3. ed. São Paulo: Edições Loyola, 1993.

LUHMANN, N. Familiarity, confidence, trust: problems and alternatives. In: GAMBETTA, D. (Ed.). Trust: making and breaking cooperative relations. New York: Basil Blackwell, 1988.

SAINSAULIEU, R. L'identite au travail. Paris: Presses de la Fondation Nationale des Sciences Politiques, 1977. 
SENNETT, R. A corrosão do caráter: conseqüências pessoais do trabalho no novo capitalismo. Rio de Janeiro: Record, 2001.

SILVA, J. R. G; VERGARA, S. C. Sentimentos subjetividade e supostas resistências à mudança organizacional. Revista de Administração de Empresas. São Paulo, v. 43, n. 3, 2003, p.10-21.

SROUR, R. H. Poder cultura e ética nas organizações. 8. ed. Rio de Janeiro: Campus, 1998.

TRIVIÑOS, A. N. S. Introdução à pesquisa em ciências sociais: a pesquisa qualitativa em educação. São Paulo: Atlas, 1987.

VASCONCELOS, I. F. F. G. ; CRUBELLATE, J. M. A desconstrução social da identidade: mudanças no trabalho e suas implicações para a identidade do trabalhador reflexivo. In: Iberoamerican Academy of Management Conference III, 2003, São Paulo. Anais... São Paulo: IberoAmerican Academy of Management, 2003, v. 1, p. 1-15.

VIEIRA, A. Identidade e crise de identidade: reflexões conceituais. In: VIEIRA, A.; GOULART, I. B. Identidade e subjetividade na gestão de pessoas. Curitiba: Juruá, 2007.

WOOD Jr., T. Mudança Organizacional: aprofundando temas atuais em administração de empresas. São Paulo: Atlas, 1995. 